\title{
How cultural values shape learning in older adulthood: the case of Malaysia
}

\begin{abstract}
Culture shapes the meaning people make of their life as well as how people experience movement through the life course. Although there is some literature on how one's culture influences the experience of older adulthood, there is little on how culture defines the nature of learning in late life. The purpose of this study was to understand how cultural values shape learning in older adulthood in the Southeast Asian country of Malaysia. A qualitative research design was employed to explore this question. Nineteen men and women between the ages of 60 and 83 were interviewed as to their experience of aging and their learning activities. Using the constant comparative method of data analysis, three themes were inductively derived from the interview data. First, older adult learning in Malaysia is nonformal and experiential Second, learning is communal. Third, much of the learning is religious or spiritual in orientation.
\end{abstract}

Keyword: Culture; Older adulthood; Learning; Malaysia 